\title{
Gendered Social Capital Guiding Women Career Planning: A Quantitative study at University of the Punjab
}

\author{
Tayyaba Sohail ${ }^{1}$, Inam-ul-Haq ${ }^{2}$, and Raja Muhammad Shoaib ${ }^{3 *}$
}

\begin{abstract}
Social capital is manifested through the relationships and networks that the human species own. Further, it is strengthened with trust and reciprocity. It inculcates the value of helping each other based on the principle of 'Mutually Beneficial Actions'. Various actors and agents play their roles in producing the social capital, yet women play the most vital role in its production due to their domestic chores, more frequent engagement with family and neighborhood. Thus, it is an essential to know that if she takes an equivalent benefit from the social capital. The primary objective of the present research determines out the role of social capital in women's career planning. The informal social networks, family, friends, and neighborhood are selected to the social capital. In the meantime, 150 female respondents from the University of the Punjab were selected using the non-probability convenience sampling technique from the final year of the Masters and Bachelors program. The findings of the study showed as the positive relation of social capital with career planning.
\end{abstract}

Keywords: Social Capital; Gender; Career Planning; Informal Networks.

\section{Introduction}

The present scholarship aims to understand the association of women's career planning with the social capital of family, friends, along with neighborhoods. Social capital is manifested through networks including formal networks (e.g., organizational associations) usually with informal networks (e.g., friends, family, \& neighbors) (Stone, 2001). The analytical focus of the current study is on informal networks as they can be the most influential in individuals' lives through regular interaction. Thus, Pakistan as the country represents the patriarchal society, and there is a greater gender imbalance in Pakistan's labor market (Javed, Syed \& Turner, 2018). Women also lack their presence in key leadership positions. Being a patriarchal society with male-dominated networks, women's choices of life are usually guided by the family members particularly male members mainly fathers, brothers often time husbands. Therefore, it will be a crucial contribution of the study to understand the role of social capital women's career planning in Pakistan society.

1 School of Social Sciences and Humanities, University of Management and Technology, Lahore. Punjab, Pakistan.

2 School of Social Sciences and Humanities, University of Management and Technology, Lahore. Punjab, Pakistan.

3 School of Social Sciences and Humanities, University of Management and Technology, Lahore. Punjab, Pakistan.

*)Corresponding Author.

Email: safii.awan7@gmail.com 
Social gathering is very common in society whereas family decisions are also influenced by the community along with the neighborhood. Thus, it can be considered that the women's lives course including career choices will be influenced by the family, peers together with neighbors. Family peers usually neighbors are the essential components of social networks besides further enhance social capital.

\section{Literature Review}

\subsection{Social Capital}

Social capital is often viewed as an endowment of the economic growth of individuals in a social group, communities including nations. Authors like Bourdieu, Coleman along with Putnam have taken social capital as the capability of the networks to provide mutual benefits for the actors. The networks can make an influence on the personal behaviors by setting informal values or norms which are shared among members of the group. Resultantly, the cooperation among members of the intra-networks along with internetworks affects economic growth. Bourdieu (1986), and Coleman (1988) along with Putnam (1993), the most renowned thinkers considered to have major contributions towards creating; moreover, familiarizing with the concept of social capital. They have discussed the various levels of the working of social capital.

Bourdieu's $(1983 ; 1986)$ analysis of social capital was at the individual along with benefits at a certain class faction level. Social capital has been categorized by him into three forms namely - economic, social closer with culture. The Marxist framework has been taken by him to examine the functioning together with the consequences of Social Capital. In addition to this, he pointed out the discriminatory access to social capital owing to power variations in the society. However, the outcomes of such social capital usually imparts the benefits to the privileged class, and the more often losses for the underprivileged class.

Coleman (1988) argued the otherwise, he projected social capital as productive, hence, concluded: the deficiencies in human capital; moreover, in the cultural capital solved through social capital. Besides, he concentrated his work on the outcomes for groups, networks, organizations, particularly for society at large. His perspective of social capital was socio-centric. He shifted the parameter of social capital to the non-elites from the elites. He highlighted the creation of social capital, the role of the family, kinship networks, subsequently religious institutions are the important in this perspective. He studied the social capital, its forms; structural conditions under which it arises by analyzing the data of dropouts from high achievers. The study significantly revealed that social capital is playing a positive role in the education of the students by reducing the probability of dropping out of high school students. Thus, he elaborated obligations, expectations; along with trustworthiness are the core functionaries of social capital which depend upon the social structures i.e., close social networks along with similarly open social networks. The 
study resulted in favor of close social networks as the same is more supportive for the production of social capital.

Another important theorist Putnam $(1993 ; 1995)$ conducted the social capital analysis at the macro level that involved community along with regional analysis. He highlighted the significance of social capital with the quality of civic life in the cultivation of a democratic society. Further, he highlighted the positive attributes of social capital as it allows citizens to resolve collective problems more easily besides facilitates the communities to advance smoothly. Moreover, the repeated interactions among people enhance trustworthiness, which consequently reduces the everyday business in addition to the social transaction cost. The social interactions among people do support them to enhance their awareness by conveying helpful information, to develop or maintain character traits for the good of society, thereby, maintaining the networks to constitute social capital. The study identified the movement of women into the labor force, residential mobility, technological transformation of leisure activities; including other demographic transformation as a few prevailing reasons for the social capital decline in the USA.

Social capital has the multiple relational dimensions namely bonding (e.g., intra-community ties- usually exist within the neighborhood) together with bridging (extra-community ties-exist between the neighborhood including other neighbor-hoods or organizations) (Lee et al., 2006; Dominguez \& Watkins, 2003; Frank, 2003; Putnam, 2002; Wuthnow, 2002). Bonding along with bridging social capital within its connecting networks like open and close channels. Close networks (permanent membership) are informal networks (family \& neighbors). Open networks are formal networks (i.e., goal-specific membership ends with target completion) (Coleman, 1988; Glickman \& Servon, 2003). Brisson (2005) considers neighborhoods as a functionary of both close systems meeting the individuals' needs within the system, as well the open settings, by building relationships with policy-makers, service organizations, along with local businesses.

Social capital signifies the ability of people to work together for common objectives in groups, organizations, usually for communities. It generates the web of social relationships as nurtured with trust, reciprocity, sometimes cooperation guided through a certain set of informal values besides norms. The norms along with values make the cognitive components of social capital, social institutions, social roles, social rules, social access, social referrals, social timings, together with networks form the structural dimension of the social capital (Grootaert \& Bastelaer 2002; Hazleton \& Kennan 2000; Uphoff, 2000). The increase in strength of social capital is dependent upon the quality of the networks. Norms of trust along with reciprocity are the defining characteristics of the quality of networks (Stone, 2001).

The preconceived roles assigned to women make them responsible for social production. She acts as a catalyst in the proliferation of social capital in kinship relations often in informal networks. Social capital is beneficial to its owners; hardly the evidence supports the argument for women. The women 
from low-income groups are the more inclined towards networking by showing high involvement in community activities: providing emotional often moral support to their relations. The social networks are the producers usually the reflectors of the power relations within a society. The elites or the powerful make these social networks: often use them accordingly for their benefits. The women remain disadvantaged in two ways - First, their networks hardly earn economic gain ; in case of business or political favors, valuable contacts typically operate through male in-groups in masculine social spaces that exclude women. They also depend upon time, along with resources whose accessibility is based on gender concerns. Second, women's social networks generally have fewer economic resources, often their key investments include time plus non-monetary labor exchanges that substituted within the domestic division of labor (Molyneux, 2002; Metz \& Tharenou 2001; Bookman, 2004). Therefore, it is an important to understand the working dynamics of social capital for the marginalized groups of the society like women, differentlyabled persons, migrants, and so forth. The in-depth analysis of the guild system suggested that the social capital of the guild proved harmful for women; since it excludes them from strong networks (Ogilvie, 2004).

The significance of social bonding is positioned in Hirschi's theory of social control. The underlying assumption is a strong "social bond" restrains social deviance. Hirschi's concept of social-bond explicates the idea that symbiotic linkages of an individual with society (attachment) encourage her/him to invest the structured time (involvement) in social structures along with institutions (commitment). This is made possible through the trust with acknowledgment of shared norms- are usually the values of the society. It indicates as social bonds produced by the social capital also act as refraining agents for individuals from the established norm, values, as a consequence accepted behaviors (Hirschi, 1977).

\subsection{Career Planning}

Social capital stock in informal networks serves as an important determinant of women's career planning. Ferry (2006) explored that the adolescent occupational choices are influenced by many factors, including life context, personal aptitudes, more often educational attainment. The cultural, social context of family along with community was found to be an effective at how youth learn about careers, often how they get influenced of making a career choice. Dick and Rallis's (1991) findings explored the career choices (e.g.,science \& engineering) of students (male, female) are influenced by the parents usually with teachers. Agarwala's (2008) studies about the career choices of Indian management students suggested: "skills, competencies along with abilities" are the most important factor more often "father" was the most significant individual influencing the career choice of Indian management students.

Social Cognitive Career Theory (SCCT), identifies self-efficacy beliefs, outcome expectations, often goal representations as the important -actors 
through which people develop, pursue and modify their career-related interests over time Lent et al. (1994; 2000). According to SCCT, high expectations are connected to the areas in which one has high self-efficacy added to outcome expectations. The development of intentions or goals for further activity exposure is based on these expectations (Lent et al., 1994).

Personal factors, such as race, sex, intelligence, cultural factors added to gender-role-socializations are the effective often considered important factors in career development. Lent et al. (2000), suggested the environmental feasibility along with limitations, be the powerful predictor of career-choice behaviors because they enable access to learning experiences, eventually creating a diversity of choice in career selection. As a result, the development of self-efficacy beliefs and an individual's learning expectations are directly affected by contextual factors. Contextual factors include the dimensions of an individual's environment likewise her/his way of perceiving along with strongly utilizing those dimensions in the facilitation of career choice as well as development.

The various investigations were conducted over the years using the SCCT; demonstrated roles of environmental supports, added with barriers, feminist attitudes, parental support, older siblings, people, along with work experiences, volunteer experiences directly affect career adoption as well choice. Parent's role emerged to be the most influential on students, yet parental involvement in career-related issues is the one of a series of factors leading youth to get involved in more intense as well effective informationseeking activities (Lent et al., 2005; Flores and O'Brien, 2002; Bender, 1994; Cochran \& Kush, 1993; Kracke, 2001; Young et al., 1997).

\subsection{Social Capital, Gender and Career Planning}

Gender roles are socially constructed social beings act in networks as per their defined roles. Therefore, the gender manifestation of social capital cannot be ignored. Social capital is usually gender-neutral. The positioning of individuals in the hierarchical networks decides the amount, level, along with the kind of extracted benefits from the social capital. Social networks are more likely to produce bonding capital for women, more kin or less non-kin relations, besides smaller networks, added to homogeneity which significantly has more negative externalities. The patriarchal structures usually keep women at disadvantageous positions by excluding them from powerful networks of trust reciprocity (Burt, 1998; Molyneaux, 2002; Mayoux, 2001; Smith, 2000). Whereas, for men; they are more likely to create bridging capital, some kin and more non-kin, larger networks plus diversity which carried more positive externalities (Lutter, 2015). Men play gatekeeper's role in social networks: bounded women's access to information is considered as one of the most important outcomes of social capital (Sappleton, 2009). Hence, the beneficial outcomes of social capital are asymmetrical for women and men.

This unequal access to social capital influences women's progress in academia in addition to their career planning up to advancement (Durbin, 2011 
\& Lipton, 2017). Career planning requires the right information at the right time in addition to mentoring facilitated and optimized through social capital (Lin \& Huang, 2005).

\subsection{Conceptual Framework for the Study}

After reviewing the existing literature, the current investigation operationalized those family-peers, besides adjacent neighbors'-social capital acts as either bonding or bridging capital for women's career planning. Women are considered the dependent on their men for their mobility. This constraint limits their direct access to information; therefore, eventually weakens their prospects of bridging capital. In order to cover the gap of bridging capital; the family starts acting as a proxy bridging social capital for women in Pakistan by connecting them to the outside world.

Furnishing lens of Hirshi's theory of social control, it was considered too: that social-capital creates a strong social bond for the women, who reinforce patriarchal norms within the social networks- often allow hardly allow them to deviate from the societal patriarchal systems. In this situation, social capital might start acting as negative for women's progress besides prosperity by limiting her access to career planning and adoption. Moreover, according to Hirschi, people do give cardinal virtue to their social network, additionally, they never risk jeopardizing by involving in any deviance. In sum, Hirschi explains that people hardly behave badly when they realize that their attitude will lose some precious people. Youth does afford any awkward from their side before teachers, parents, along with a friend, whatever presented them arrogant; perhaps they hide their crimes too-because their opinion matters a lot often causes worst consequences. Similarly, adults refrain from deviance: extramarital relations to save their job as well marriage - bonds that, again, must serve as sources of social control. On the other hand, if it acts positively then, women can reap the benefits of social capital - whatever can play a vital role in society's success (Hirschi, 1969).

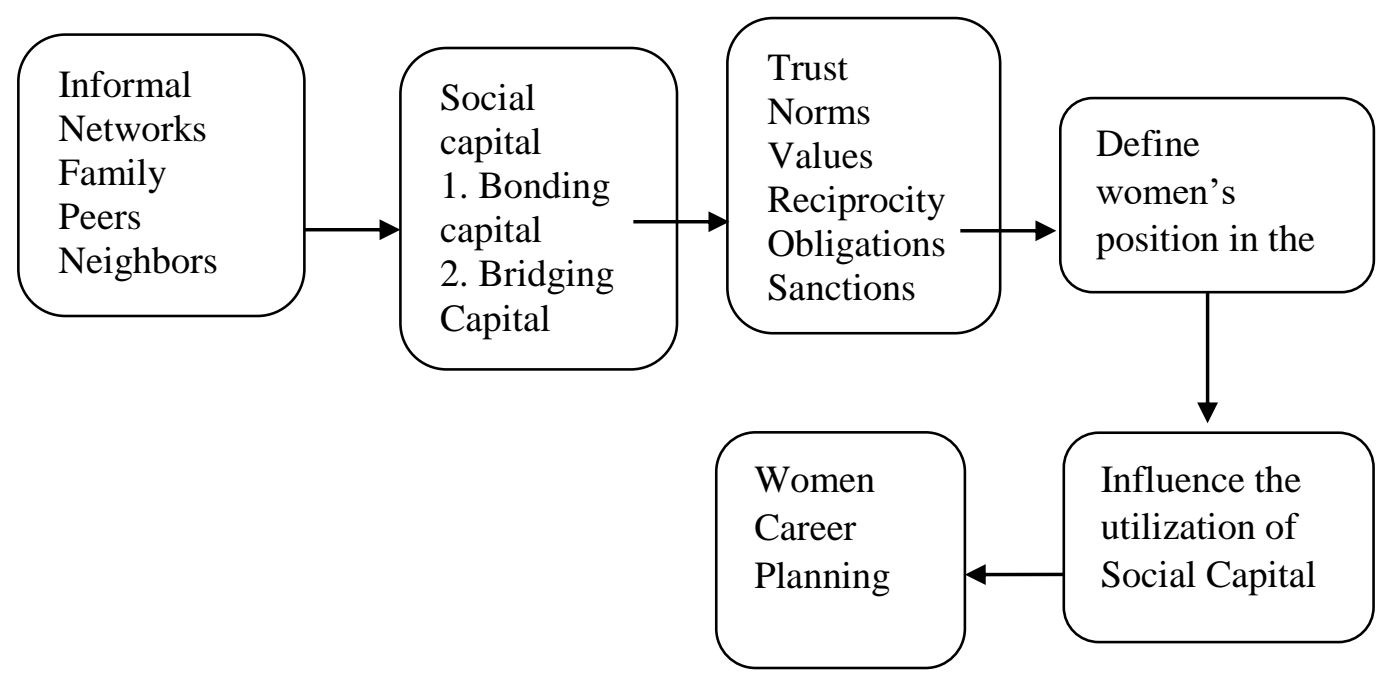


In the light of all the above-mentioned the empirical and theoretical studies, the researcher draws the following conceptual framework for conducting the present study. Social capital is manifested in a mechanism in addition to networks along with relations that define certain norms, rules, in addition to roles for the members of the networks. Individuals follow the rules besides this, they behave according to their ascribed roles after the norms defined by their associations. These norms, roles, in addition to rules are reinforced by sanctions or incentives. Thus, to attain in addition to maintain an acceptable position in a group: human beings develop social strategies; adapted to the needs of the social worlds; they dwell in. Moreover, individuals try to learn what conditions make it the possible for them, nevertheless not to aspire to what is not available to them. The most unlikely practices are therefore, excluded, as unthinkable, by a kind of an immediate submission to incline individuals to make a virtue of necessity, to refuse categorically denied social norms, and will be inevitable for its associations.

Social exchange patterns, interactions, besides relations develop obligations among individuals. Obligations include commitments of individuals to help each other yet practice the actions whichever have conformity with the group activities. However, it includes the individual's contribution to mutually beneficial actions. Individuals are obliged to fulfill their expected responsibilities as their behavior is confirmed by the sanctions/incentives.

Sanctions/ incentives vary with the level of familiarity added to closeness. Familiarity further defines the level of the kind of trust among individuals usually thus, affects the types of obligations. Using the frameworks of Bourdieu's social capital theory $(1977 ; 1990)$, added with the social control theory of Hirschi's $(1969 ; 1977)$ the authors of the present scholarship observed that the significant model of social capital produces inequalities beside the strong bonding of the relations provides people with less opportunity to own their individual decisions respectively.

Inequalities are produced with the greater access; more often ownership of economic resources as well social resources. The social resources include;

- $\quad$ Strong ties within a network (Strong Bonding)

- $\quad$ Access to other networks (Bridging, Linking)

- $\quad$ Control over networks

- Influence over network decisions

Individuals having greater control over economic and social resources usually happen to be more influential in defining the norms, rules, at last, yet not the least roles of the individuals in networks along with the relations. In the same way, somehow have power over the whole mechanism of social capital by influencing sanctions/interventions more particularly obligations. 
If the same model of social capital is seen with special attention to the gender relations, the observations will describe the females enjoy the different benefits from the social capital as her role seems to be a homemaker within the structural boundary of the house besides serving a family that is her priority which decreases her access and control over social in addition to economic resources. The same issues of women's position in social networks: the gender-differentiated consequences of social capital were raised in empirical studies conducted by (Silvey \& Elmhirst, 2003; Bookman, 2004; Molyneux, 2002; Metz \& Tharenou, 2001).

The present study analyzed the influence of the social capital model on the planning of career adoption of women. Using the contextual factor of the SCCT framework researcher looks into predefined roles of women as a serving agent for their families or communities that influence their chances of career adoption. Contextual factors not only include the parents, a family usually includes friends. It also increases the range of factors to other prevailing norms in the society. Thus, unfortunately, social circle (e.g., socalled social capital) besides contextual factors decides about her career planning; that influences her to access economic resources. It affects her social resource access consequently often at the end of the day, produces the difference.

\section{Research Design}

\subsection{Population and Sample}

Quaid-e-Azam Campus, University of the Punjab - Lahore is the universe of the study. The selected participants belong to the largest public university. Being the largest and public: the university accommodates the maximum diversity of students across Pakistan. Moreover, students getting higher education from large yet reputable institutions set higher career goals; subsequently, achieve them successfully in their practical lives. Therefore, the same assumption is being applied to the female students studying at Punjab University (Hafsyan, 2015). Thus, females enrolled at the Punjab University are the population of the study. In the meantime, 150 participants are selected through the non-probability convenience sampling technique using $\mathrm{G}^{*}$ Power.

\subsection{Sample inclusion and exclusion Criteria}

The study included a yearly based system or the semester-based students considering them near to their degree completion; therefore, they are seeking the guidance from their families for the jobs, and probably are dropping the resumes. Thus, their experiences assisted the maximum accurate information. 1st year of the M.A program and Bachelors programs were excluded from the study. 


\subsection{Instrument}

The self-constructed questionnaire as employed to collect the cultural contextual information. A total of 24 items were included in the tool. According to the scope of the study, the tool was further sub-divided into three subscales namely; family social capital comprised of Four items, e.g., "Have you discussed your career plans with your family", peers social capital consisted of nine items, e.g., "Do your friends encourage you for higher studies" besides neighbor's social-capital, which included 12 items, e.g., " Do your neighbors encourage higher-education". The dichotomous rating scale was used whereas 01 represents "No" and 02 represent "Yes". The Cronbach's alpha for family social capital, peers social capital, and neighbors social capital were $.61, .70$, and .74 respectively.

\subsection{Ethical Considerations}

The overall ethical considerations were observed in this respect. The participants of the research made a brief explicitly about the academic nature of the research. The anonymity of the participant besides confidentiality of the participant was respected during the research course. The honesty was highly maintained in reporting and analysis of the data.

\section{Results}

The variables were converted into scaled score prior to data analysis to attain the homogeneity among scores.

Table. 1 Descriptive Statistics of Demographic and Study Variables (N=140)

\begin{tabular}{lll}
\hline Variables & $\mathrm{f}(\%)$ & $\mathrm{M}(\mathrm{SD})$ \\
\hline Age & & 21.62 \\
Department & $24(17.1)$ & \\
Natural Science & $40(28.6)$ & \\
Business & $76(54.3)$ & \\
Social Science & & \\
Program & $48(34.3)$ & \\
Masters & $92(65.7)$ & \\
Bachelors & & \\
Semester & $49(41.3)$ & \\
4-5 & $63(45)$ & \\
6-7 & $25(17.8)$ & \\
8 and above & & \\
Family Structure & $92(65.7)$ & \\
Nuclear & $48(34.3)$ & \\
Joint & & \\
Monthly & $19(13.6)$ & \\
Below 15, 000 & $45(32.1)$ & \\
15,001 - 35, 000 & $29(20.7)$ & \\
35,001 - 55, 000 & $44(31.4)$ & \\
Above 55, 000 & & \\
Family and Career Planning & &
\end{tabular}


Neighbors and Career Planning

Table. 2 One-Way Repeated Measure ANOVA Comparing Informal Network (Family, Neighbors and Friends) and Career Planning (N=140)

\begin{tabular}{|c|c|c|c|c|c|}
\hline \multirow{3}{*}{ Variable } & \multicolumn{3}{|c|}{ Informal Network } & \multirow[b]{3}{*}{$F(2,278)$} & \multirow{3}{*}{$\begin{array}{l}\text { Partial } \\
\eta^{2}\end{array}$} \\
\hline & Family & Neighbors & Friends & & \\
\hline & $M(S D)$ & $M(S D)$ & $M(S D)$ & & \\
\hline Career Planning & $8.71(1.59)$ & $2.92(0.48)$ & $3.09(0.39)$ & $1753.23^{*}$ & 0.927 \\
\hline
\end{tabular}

Table. 2 Results presented the significant differences among informal networks and career planning with a large effect size. Comparison in pairs revealed; consultation with family resulted in better career planning as compared to career planning in consultation with friends and neighbors.

Table. 3 One-Way Independent Measure ANOVA Comparing Subject Choice in Career Planning $(\mathrm{N}=140)$

$* \mathrm{p}<.05$

Note. Partial $\eta 2=$ effect size

Table. 3 (Table three) significantly found differences between department and neighbor's career planning with medium effect size. Whereas pair-wise comparisons Post Hoc (Hochberg's GT2) analysis was carried out, it indicates that students opted for natural sciences as a result of neighbor career planning. Furthermore, non-significant differences were found between departments and informal networks (i.e., Family and Friends), and career planning.

\section{Discussion}

Collectivism is the foundation element of Pakistani society. Family and friends along with neighbors make an important composite of individuals' lives. Compliance with the norms of the family and friends, besides neighbors as considered an integral of Pakistani culture. People are often dependent to take decisions, even though they do consult their informal networks (e.g., family, peers, \& neighbors) along with avoiding the unacceptable acts by that networks (Islam, 2004). Since Pakistani society is patriarchal-culturally, therefore, prevailing norms of the society advantage the male; therefore, networks are usually male dominant. Balanced accumulation of bridging and bonding capital is an important to extract the benefit of the network (EklinderFrick, Eriksson, \& Hallén, 2012). The acceptable confinement of females in domestic spheres, socio-religious obligations of avoiding males other than family, following fixed time for returning home (e.g., avoiding staying outside 
the home after sunset), and so forth., make it sometimes difficult for women to accumulate along with reap benefits of bridging capital (Rehman \& Azam, 2012).

This not only limits their career options yet minimizes their access to the accumulation of social capital. In alignment with this, the findings of the study also suggest that family social capital plays a more vital role in women's career planning as compared to peers besides neighbors. Since Jomaa (2020) explained per Islam, the neighbor is a friend; a friend ought to be protected whereas one hardly shows the aggression towards a neighbor. Aggression against any human shall be considered a sin near to God Almighty.

People strongly follow the religion- Islam, though; they do know that Islam gives an immense reverence to neighbors. This belonging makes them more caring for others, this care creates a mess, therefore; people start intruding on the issues of other people. Women are influenced by their friends and by their neighbors since neighbors in local culture carry an important role; at times they become intrusive in the matters of others.

Despite all the patriarchal societal norms, the study resulted as a positive association of social capital with career planning. Family social capital for women acts as bonding and bridging capital of women. Peer associations seem a positive factor in getting hold of bridging social capital. Unless one cannot bypass that peers- belong to the same age group with more or less the same kind of social resources. Therefore, they are considered a good motivational source; nevertheless beneficial to access to jobs along with career adoption. Family social capital seems to play a positive role in guiding their daughters and siblings about their career planning. It reflects that society's acceptance level regarding women's career planning is changing. The neighborhood is forever, considered an immense beneficial social capital. The extended networks in the form of the neighborhood seem encouraging in women's career planning. The increased connections with the neighborhood encourage women's career planning.

This paper pointed out that we have to accept diversity in the context of social capital. Women are also complete human beings, rather than a number among many. We have a charter in the shape of the Qur'an, which endorses diversity as enriching human knowledge about their differences rather than dealing with them behind a "veil of ignorance" (Jomaa, 2020).

\section{Conclusion}

The present scholarship attempts to contextualize the informal social capital, within the social dynamics of gender in Pakistani society. The societal attitudes towards women are changing with time. The practical implications of the study do suggest, that awareness campaigns are of utmost need in media, civil society organizations, and particularly in academia that categorically encourage families to eliminate social hurdles for the women in the family to pursue their academic and career goals. Gender-sensitive men enable women to access social networks, therefore, make them beneficial for them. NGOs 
that are working on women empowerment, social capital projects, or community development projects -need to incorporate gender-sensitive social networks so that women avail full advantage of the social networks and social capital.

\section{References}

Agarwala, T. (2008). Factors influencing career choice of Management students in India. Career Development International, 13(4), 362-376. doi:10.1108/13620430810880844

Bender, S. (1994). Female Student Career Aspirations in Science. SSTA Research Centre Report\# 94-04. SSTA Research in Brief. https://eric.ed.gov/?id=ED372954

Bookman, A. (2019). Starting in our own backyards: how working families can build community and Survive the new economy. Routledge, 336. doi:https://doi.org/10.4324/9780203497364

Bookman, A. (2004). Starting in our own backyards: How working families can build community and survive the new economy. Routledge.

Bowen, G. L., Martin, J. A., Mancini, J. A., \& Nelson, J. P. (2000). Community capacity: Antecedents and consequences. Journal of Community Practice, 8(2), 1-21. doi:10.1300/j125v08n02_01

Bourdieu, P. (1980). Le capital social: notes provisoires. Actes de la recherche en sciences sociales, 31(1), 2-3.

Bourdieu, P. (1986). The Forms of Capital, in: J. G. Richardson (Ed) Handbook of Theory and Research for the Sociology of Education, pp. 241-258. New York, Westport, CT., Greenwood Press.

Brisson, D. S., \& Usher, C. L. (2005). Bonding social capital in low-income neighborhoods. Family Relations Retrieved Fromhttps://mcstudy.norc.org/publications/files/brisson $\% 20$ and $\% 20 \mathrm{u}$ sher.pdf

Burt, R. S. (1998). The gender of social capital. Rationality and Society, 10(1), 5-46. doi:10.1177/104346398010001001

Coleman, J. S. (1988). Social capital in the Creation of human capital. American Journal of Sociology, 94, 95-120. doi:10.1086/228943

Dick, T. P., \& Rallis, S. F. (1991). Factors and influences on high school STUDENTS' career choices. Journal for Research in Mathematics Education, 22(4), 281-292. doi:10.5951/jresematheduc.22.4.0281

Domínguez, S., \& Watkins, C. (2003). Creating networks for survival and Mobility: Social capital AMONG African-American AND LatinAmerican low-income mothers. Social Problems, 50(1), 111-135. doi:10.1525/sp.2003.50.1.111

Durbin, S. (2011). Creating knowledge through networks: A Gender Perspective. Gender, Work \& Organization, 18(1) 90-112. doi:https://doi.org/10.1111/j.1468-0432.2010.00536.x http://www.worldbank.org/wbp/scapital/sources/gender1.htm\#maw 
Eklinder-Frick, J., Eriksson, L. T., \& Hallén, L. (2012). Effects of social capital on processes in a regional strategic network. Industrial Marketing Management, 41(5), 800-806. doi:10.1016/j.indmarman.2012.06.007

Ferry, N. M. (2006). Factors Influencing Career Choices of Adolescents and Young Adults in Rural Pennsylvania. Journal of Extension, 44(3), 1-6.

Flores, L. Y., \& O'Brien, K. M. (2002). The career development of Mexican American ADOLESCENT women: A test of social cognitive career theory. Journal of Counseling Psychology, 49(1), 14-27. doi:10.1037/0022-0167.49.1.14

Frank, J. (2003). Making social capital work for public policy. Horizons, 6(3), 3-6.

Glickman, N. J., \& Servon, L. J. (2003). By the numbers: Measuring community development corporations' capacity. Journal of Planning Education and Research, 22(3), 240-256. doi:10.1177/0739456x02250314

Grootaert, C., \& Van Bastelaer, T. (Eds.). (2002). Understanding and measuring social capital: A multidisciplinary tool for practitioners (Vol. 1). Washington DC, USA: World Bank Publications.

Hafsyan, A. S. (2015). Educational and Career Aspirations of University Honors and Non- Honors Student (Doctoral dissertation, University of Connecticut, 2015). Retrieved from https://opencommons.uconn.edu/dissertations/687

Hazleton, V., \& Kennan, W. (2000). Social capital: Reconceptualizing the bottom line. Corporate Communications: An International Journal, 5(2), 81-87.

Helliwell, J. F., \& Putnam, R. D. (1995). Economic growth and social capital in Italy. Eastern economic journal, 21(3), 295-307. 312-342. https://doi.org/10.1177/1059601101263005

Hirschi, Travis (1969). Causes of Delinquency. Berkeley and Los Angeles: Berkeley, University of California Press.

Hirschi, Travis and Michael J. Hindelang (1977). Intelligence and delinquency; a revisionist review. American Sociological Review 42:571-87.

Islam, N. (2004). Sifarish, sycophants, power and collectivism: Administrative culture in Pakistan. International Review of Administrative Sciences, 70(2), 311-330.

Javed, S., Syed, J., \& Turner, R. (2018). Gender, employment and careers in Pakistan. In Research Handbook of Diversity and Careers. Edward Elgar Publishing.

Jomaa, K. (2020). Social Justice and Islamic Legal/Ethical Order: The Madinah Constitution as a Case Study from the Prophetic Period. In Vishanoff D. (Ed.), Islamic Law and Ethics (pp. 162-206). Washington: International Institute of Islamic Thought. doi:10.2307/j.ctv19prr5b.11 
Kracke, B (2011), Parental behaviors and adolescents career exploration, The Career Development Quarterly, 45(4), 341-350. Retrieved From https://doi.org/10.1002/j.2161-0045.1997.tb00538.x

Kush, K., \& Cochran, L. (1993). Enhancing a sense of agency through career planning. Journal of Counseling Psychology, 40(4), 434-439. doi:10.1037/0022-0167.40.4.434

Lee, J., \& Bowen, N. K. (2006). Parent involvement, cultural capital, and the achievement gap among elementary school children. American Educational Research Journal, 43(2), 193-218. doi:10.3102/00028312043002193

Lent, R. W., Singley, D., Sheu, H., Gainor, K. A., Brenner, B. R., Treistman, D., \& Ades, L. (2005). Social cognitive predictors of domain and life satisfaction: Exploring the theoretical precursors of subjective wellbeing. Journal of Counseling Psychology, 52(3), 429-442. doi:10.1037/0022-0167.52.3.429

Lent, R. W., Brown, S. D., \& Hackett, G. (1994). Toward a unifying social cognitive theory of career and academic Interest, choice, and performance. Journal of Vocational Behavior, 45(1), 79-122. doi:10.1006/jvbe.1994.1027

Lent, R. W., Brown, S. D., \& Hackett, G. (2000). Contextual supports and barriers to career choice: A social cognitive analysis. Journal of Counseling Psychology, 47(1), 36-49. doi:10.1037/0022-0167.47.1.36

Lin, S., \& Huang, Y. (2005). The role of social capital in the relationship between human capital and career mobility: Moderator or mediator? Journal of Intellectual Capital, 6(2), 191-205. doi:10.1108/14691930510592799

Lipton, B. (2017). Measures of success: Cruel optimism and the paradox of academic women's participation in Australian higher education. Higher Education Research \& Development, 36(3), 486-497. doi:10.1080/07294360.2017.1290053

Lutter, M. (2015). Do women suffer from Network Closure? The moderating effect of social capital on gender inequality in a Project-Based labor Market, 1929 to 2010. American Sociological Review, 80(2), 329-358. doi:10.1177/0003122414568788

Mayoux, L. (2001). Tackling the down Side: Social capital, women's empowerment and micro finance in Cameroon. Development and Change, 32(3), 435-464. doi:10.1111/1467-7660.00212

Metz, I., \& Tharenou, P. (2001). Women's Career Advancement: The Relative Contribution of Human and Social Capital. Group \& Organization Management, 26(3),

Molyneux, M. (2002). Gender and THE SILENCES of social Capital: Lessons from Latin America. Development and Change, 33(2), 167-188. doi:10.1111/1467-7660.00246 
Ogilvie, S. (2004). How does social CAPITAL affect WOMEN? Guilds and communities in early Modern Germany. The American Historical Review, 109(2), 325-359. doi:10.1086/530335

Putnam, R. (1993). The prosperous community: Social capital and public life. The American prospect, 13(Spring), Vol. 4. Available online: http://www.prospect.org/print/vol/13

Putnam, R. D. (1995). Tuning in, Tuning out: The Strange disappearance of social capital in America. PS: Political Science and Politics, 28(4), 664-684. doi: $10.2307 / 420517$

Putnam, R. D. (2002). Democracies in flux: The evolution of social capital in contemporary society. Oxford University Press. doi:10.1093/0195150899.001.0001

Rehman, S., \& Azam Roomi, M. (2012). Gender and work-life balance: A phenomenological study of women entrepreneurs in Pakistan. Journal of Small Business and Enterprise Development, 19(2), 209-228. doi:10.1108/14626001211223865.

Sappleton, N. (2009). Women non-traditional entrepreneurs and social capital. International Journal of Gender and Entrepreneurship, 1(3), 192-218. doi:10.1108/17566260910990892

Silvey, R., \& Elmhirst, R. (2003). Engendering social capital: Women workers and rural-urban networks in Indonesia's crisis. World development, 31(5), 865-879.

Smith, S. S. (2000). Mobilizing social Resources: Race, ethnic, and gender differences in social capital and persisting wage inequalities. The Sociological Quarterly, 41(4), 509-537. doi:10.1111/j.15338525.2000.tb00071.x

Stone, W. (2001). Measuring social capital: Towards a theoretically informed measurement framework for researching social capital in family and community life. Australian Institute of Family Studies, 24, 1-35. Retrieved from www.aifs.org.au/

Uphof, N. (2000). Understanding social capital: Learning from the analysis and experience of participation. Institutional Analysis. Retrieved from https://www.ircwash.org/sites/default/files/Uphoff-2000Understanding.pdf

Wuthnow, R. (2002). Religious involvement and status-bridging social capital. Journal for the Scientific Study of Religion, 41(4), 669-684. doi:10.1111/1468-5906.00153

Young, R. A., Valach, L., Paseluikho, M. A., Dover, C., Matthes, G. E., Paproski, D. L., \& Sankey, A. M. (1997). The joint action of parents and adolescents in conversation about career. The Career Development Quarterly, 46(1), 72-86. https://doi.org/10.1002/j.21610045.1997.tb00693.x 